\title{
MicroRNA-363-3p inhibits cell proliferation and induces apoptosis in retinoblastoma cells via the Akt/mTOR signaling pathway by targeting PIK3CA
}

\author{
XIAOJIE MA ${ }^{1}$, LAN JIN ${ }^{1}$, XIAOQIN LEI $^{2}$, JINGAN TONG ${ }^{3}$ and RUNSHENG WANG ${ }^{2}$ \\ ${ }^{1}$ Department of Ophthalmology, Xi'an Hospital of Traditional Chinese Medicine, Xi'an, Shaanxi 710021; \\ ${ }^{2}$ Department of Ophthalmology, Xi'an No. 4 Hospital, Xi'an, Shaanxi 710004; ${ }^{3}$ Department of Ophthalmology, \\ The First Affiliated Hospital of Shaanxi University of Chinese Medicine, Xianyang, Shaanxi 712000, P.R. China
}

Received September 21, 2017; Accepted December 19, 2019

DOI: $10.3892 /$ or.2020.7544

\begin{abstract}
There is extensive evidence suggesting that microRNAs (miRs) can modulate the activity of oncogenes and tumor suppressors, and are associated with the occurrence of cancer. In the present study, the function of miR-363-3p in the progression of retinoblastoma (RB) was investigated. miR-363-3p expression in RB was decreased, and miR-363-3p protein levels were found to be inversely correlated with phosphatidylinositol-4,5-bisphosphate 3-kinase catalytic subunit $\alpha$ (PIK3CA) levels. Overexpression of miR-363-3p in an in vitro model of $\mathrm{RB}$ revealed that miR-363-3p had anticancer effects on RB and regulated PIK3CA, pyruvate dehydrogenase kinase 1 (PDK1) and phosphorylated protein kinase B (p-AKT) protein expression. Downregulation of miR-363-3p promoted cell proliferation of RB cells through PIK3CA, PDK1 and p-AKT protein expression. Knockdown of PIK3CA increased the anticancer effects of miR-363-3p in RB cells. Treatment with OSU-03012, a PDK1 inhibitor, accelerated the anticancer effects of miR-363-3p in RB cells. Taken together, the results demonstrate that miR-363-3p functions as a tumor suppressor in RB by targeting PIK3CA.
\end{abstract}

\section{Introduction}

Retinoblastoma (RB) is the most common type of intraocular malignant tumor among children, and it seriously affects the vision of these children and is associated with a poor patient prognosis (1). The main clinical manifestation is a white pupil, and the pathogenesis is widely accepted to be due to mutations in the two copies of the $R B$ gene (2). RB has always

Correspondence to: Mr. Lan Jin, Department of Ophthalmology, Xi'an Hospital of Traditional Chinese Medicine, 69 Fengcheng 8th Road, Xi'an, Shaanxi 710021, P.R. China

E-mail: 32844610@qq.com

Key words: microRNA-363-3p, retinoblastoma, PIK3CA, AKT, 3-phosphoinositide-dependent protein kinase-1 been considered to be the ideal model for studying tumor genetics and tumor pathogenesis (1). The $R B$ gene was the first to be identified as a tumor-suppressor gene in humans. With continued research, novel methods for the effective prevention and treatment of the disease may be identified through a deeper exploration into the pathogenesis of $\mathrm{RB}$ at the molecular biology level (3).

microRNAs (miRNAs/miRs) are a family of mature non-coding RNA molecules composed of 21-25 nucleotides that can modulate target gene expression by cleaving the target mRNA or inhibiting protein synthesis to cause post-transcriptional gene silencing (4). As gene regulators, miRNAs can affect a variety of cellular pathways and functions, and early studies showed that miRNAs have an impact on gene expression during development, cell death and proliferation, and formation of the immune and nervous systems (5). The current understanding is that miRNAs play an important role in the occurrence of many diseases (5). A previous study demonstrated that miRNAs are expressed in human tumor cells and are classified into tumor-suppressor genes or oncogenes according to their roles in tumor cell transformation and gene expression (6). miRNA genes are located in the fragile sites of the human genome, thus they may be mutated easily in the cancer genome as it accumulates damage (4-6). miRNAs play a role in the regulation of proliferation, differentiation and apoptosis of tumor cells (4).

The phosphoinositide 3-kinase (PI3K) signaling pathway plays a role in the formation of a variety of tumors. Activation of PI3K signaling leads to phosphorylation of protein kinase B (AKT) and activation of the downstream signaling pathway, as well as regulation of cell growth, reproduction, migration and apoptosis (7). Members of the PI3K signaling pathway are frequently observed to be abnormally expressed in a variety of solid tumors (7). Mutations in the helical domain of the protein of the phosphatidylinositol-4,5-bisphosphate 3-kinase catalytic subunit $\alpha$ (PIK3CA) gene, in exon 9, and mutations in the kinase domain in exon 20 may upregulate PI3K signaling and facilitate tumorigenesis (8). It has been reported that increased copy number and mutation of the PIK3CA gene occur in lung cancer, suggesting that the two types of genetic alterations may play a role in the formation 
of RB (8). PIK3CA is an oncogene that has been confirmed in recent years, and mutations in PIK3CA may be involved in the regulation of carcinogenesis (9). Mutations in the PIK3CA gene have been identified in $\sim 30 \%$ of solid tumors, and the mutation of this gene can increase the kinase activity of the enzyme, activate AKT, reduce apoptosis and contact inhibition, promote tumorigenesis and increase tumor invasiveness (10). A study by Liu et al (11) indicated that miR-363-3p inhibits papillary thyroid carcinoma progression by targeting PIK3CA. The present study was designed to ascertain whether miR-363-3p regulates the PIK3CA signaling pathway in RB and if it exerts anticancer effects in regards to this disease.

\section{Materials and methods}

Patient samples. The serum samples of patients and normal controls were collected from May 2016 to December 2016 at the Xi'an Traditional Chinese Medicine Hospital (Xi'an, Shaanxi, China) (Table I). The peripheral blood $(10 \mathrm{ml})$ of all samples was centrifuged at $1,000 \mathrm{x}$ for $10 \mathrm{~min}$ at $4^{\circ} \mathrm{C}$, and then serum was collected. Serum was immediately frozen in liquid nitrogen, and stored at $-80^{\circ} \mathrm{C}$. The study protocol was approved by the Medical Ethics Committee of Xi'an Traditional Chinese Medicine Hospital (Xi'an, Shaanxi, China).

$R N A$ isolation and quantitative real-time PCR $(R T-q P C R)$ analysis and microarray analysis. Total RNA was extracted from serum and cells using TRIzol reagent (Invitrogen; Thermo Fisher Scientific, Inc.). cDNA synthesis was carried out using a RT kit (Takara Biotechnology Ltd.). MicroRNA-363-3p expression was quantified by using SYBR Premix Ex TaqTM (Takara) under ABI 7500 Fast Sequence Detection System (Applied Biosystems Prism; Thermo Fisher Scientific, Inc.).

Microarray analysis was performed using Illumina, HT-12 v4.0 platform (Bencos Research Solutions). Total RNA was extracted from serum and cells using Trizol reagent (Invitrogen; Thermo Fisher Scientific, Inc.). Gene expression analysis was performed commercially using Illumina, HT-12 v4.0 platform and expression of genes was analyzed using R 3.1.2 (www.r-project.org).

Cell, plasmids and transfections. Human RB WERI-Rb-1 cell line (Shanghai Cell Bank, Chinese Academy of Sciences) was cultured in RPMI-1640 medium (Invitrogen; Thermo Fisher Scientific, Inc.) containing $10 \%$ fetal bovine serum (FBS; Invitrogen; Thermo Fisher Scientific, Inc.) and 1\% penicillin-streptomycin at $37^{\circ} \mathrm{C}$ in a humidified $5 \% \mathrm{CO}_{2}$ incubator. MicroRNA-363-3p plasmid and negative plasmid were purchased from Shanghai Gene-Pharma Co. The microRNA-363-3p plasmid (50 ng) and negative plasmid $(50 \mathrm{ng})$ were transfected into WERI-Rb-1 cells using Lipofectamine 3000 (Invitrogen; Thermo Fisher Scientific, Inc.) according to the manufacturer's instructions.

Cell growth assay. Cell proliferation $\left(1 \times 10^{3}\right.$ cells/well) was assessed using the MTT assay $(0.5 \mathrm{mg} / \mathrm{ml}$; Sigma-Aldrich; Merck $\mathrm{KGaA}$ ) for $4 \mathrm{~h}$ at $37^{\circ} \mathrm{C}$ and DMSO was added into the cells for $20 \mathrm{~min}$ at $37^{\circ} \mathrm{C}$. Absorbance was then recorded using a microplate reader (Bio- $\mathrm{Rad}$ ) at $490 \mathrm{~nm}$.
Table I. Characteristic of the patients with retinoblastoma (RB).

\begin{tabular}{lcc}
\hline Variables & $\begin{array}{c}\text { Normal control } \\
\text { subjects }(\mathrm{n}=6)\end{array}$ & RB patients $(\mathrm{n}=6)$ \\
\hline Mean age (years) & $57.9 \pm 2.5$ & $55.8 \pm 3.8$ \\
Sex & & \\
Female & 3 & 3 \\
Male & 3 & 3 \\
Edmondson grade & & \\
I & 0 & \\
II & 0 & 1 \\
III & 0 & 3 \\
IV & 0 & 2 \\
V & 0 & \\
\hline
\end{tabular}
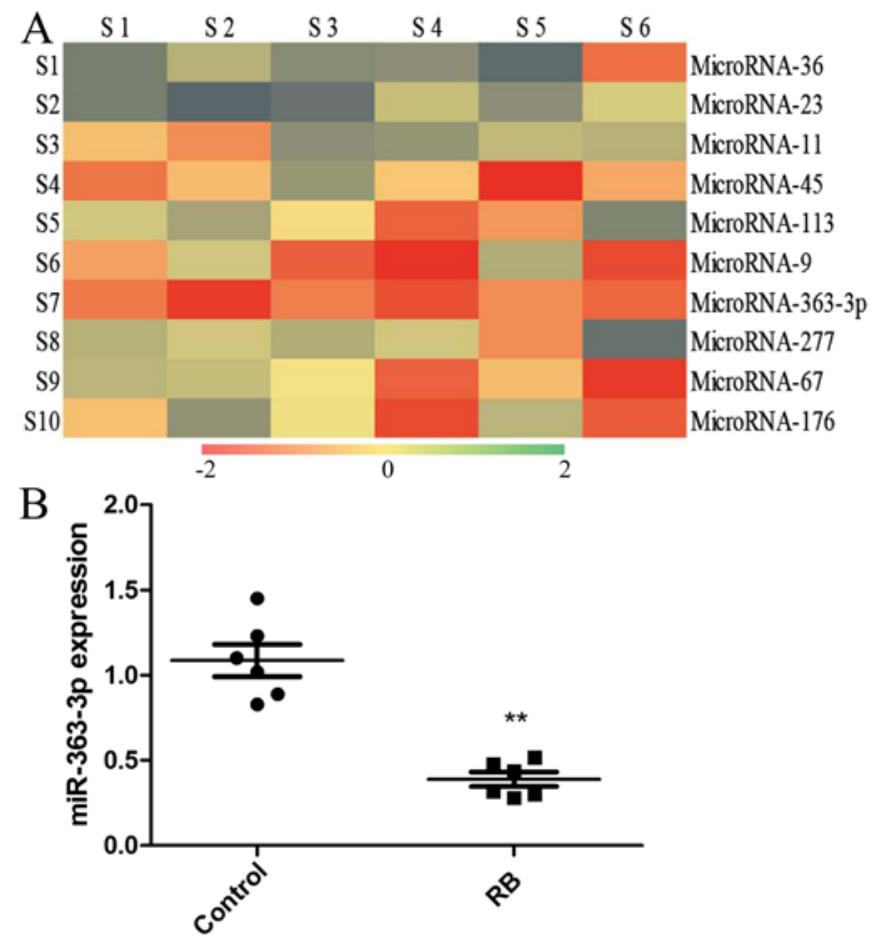

Figure 1. miR-363-3p levels in RB patient serum. (A) MicroRNA expression using Gene chip and (B) miR-363-3p expression levels in RB and control groups. RB, retinoblastoma serum group; Control, normal control group. ${ }^{* *} \mathrm{P}<0.01$ compared with the normal control group.

Cell apoptosis. The cells $\left(1 \times 10^{6}\right.$ cells/well) were washed with PBS and cells were resuspended with dilute binding buffer (BD Biosciences). Cells were stained with $5 \mu$ l Annexin V and $5 \mu \mathrm{l}$ propidium iodide (PI) (BD Biosciences) for $15 \mathrm{~min}$ at room temperature. Cell apoptosis were detected by LSRII flow cytometer (BD Biosciences) and analyzed by FlowJo 3.1 (Tree Star, Ashland, OR, USA).

Cell invasion assays. The cells $\left(1 \times 10^{6}\right.$ cells/well $)$ were seeded into the upper chamber of Matrigel-coated inserts and RPMI-1640 medium containing $10 \%$ FBS was added to the lower chamber 

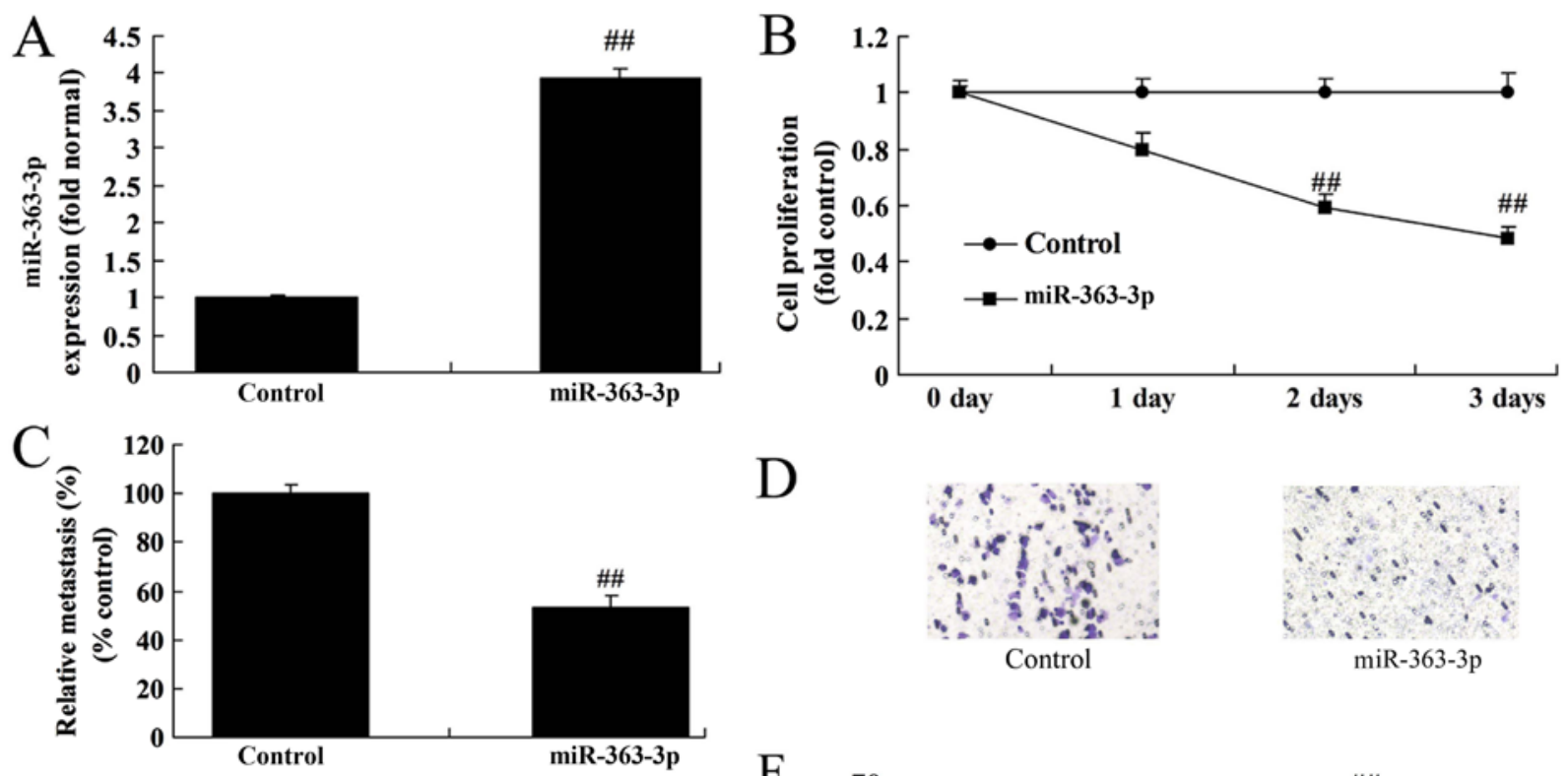

$\mathrm{D}$
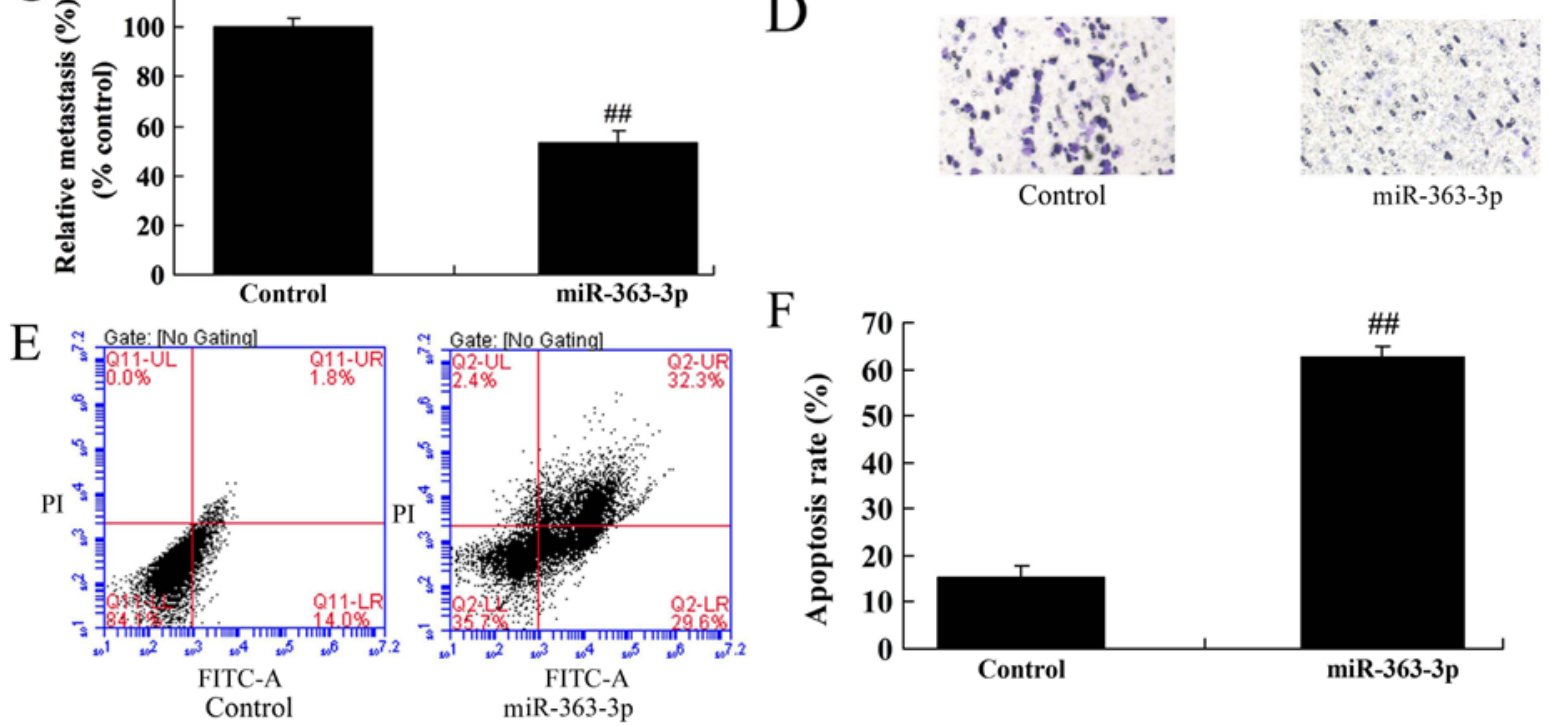

Figure 2. Overexpression of miR-363-3p reduces RB cell growth and invasion. (A) miR-363-3p expression in human RB WERI-Rb-1 cell line after transfection of miR-363-3p mimics. (B) Cell proliferation in the miR-363-3p-overexpressing RB cells. (C and D) Invasion ability in the miR-363-3p-overexpressing RB cells. (E and F) The apoptosis rate in the miR-363-3p-overexpressing RB cells. Control, negative control group; miR-363-3p, miR-363-3p overexpression group. $\mathrm{RB}$, retinoblastoma. ${ }^{\# \#} \mathrm{P}<0.01$ compared with the negative control group.

at $37^{\circ} \mathrm{C}$ in a humidified $5 \% \mathrm{CO}_{2}$ incubator for $48 \mathrm{~h}$. The lower surface cells were fixed in $70 \%$ ethanol for $30 \mathrm{~min}$ and stained with $0.1 \%$ crystal violet for $10 \mathrm{~min}$. Cells were observed under an X71 inverted microscope (Olympus Corporation).

Western blot analysis. Total protein was extracted from the cells using RIPA Kit and protein concentrations of the sample were quantified using a BCA protein quantification kit. An amount of $40 \mu \mathrm{g}$ protein was separated by $8-12 \%$ SDS-PAGE and transferred to a PVDF membrane. The membrane was blocked with 5\% skim milk in TBST for $1 \mathrm{~h}$ at room temperature and incubated with primary antibodies: anti-Bax (cat. no. sc-6236, dilution 1:1,000, Santa Cruz Biotechnology), anti-PIK3CA (cat. no. 4249, dilution 1:2,000, Cell Signaling Technology, Inc.), anti-PDK1 (cat. no. sc-376586, dilution 1:1,000, Santa Cruz Biotechnology), anti-p-Akt (cat. no. 4060, dilution 1:2,000, Cell Signaling Technology, Inc.) and GAPDH (cat. no. 5174, dilution 1:5,000, Cell Signaling Technology, Inc.) at $4^{\circ} \mathrm{C}$ overnight. Membrane was washed with TBST and incubated with anti-rabbit (cat. no. sc-2030) or anti-mouse (cat. no. sc-2031) secondary antibodies (dilution 1:5,000, Santa Cruz Biotechnology) for $2 \mathrm{~h}$ at room temperature. Protein blank was detected using the enhanced chemiluminescence (ECL) method and analyzed using Image Lab 3.0 (Bio-Rad Laboratories, Inc.).
Caspase-3/9 activities. Total protein was extracted from the cells $\left(1 \times 10^{6}\right.$ cells/well) using the RIPA Kit and protein concentrations of the sample were quantified by the BCA protein quantification kit. A total of $5 \mu \mathrm{g}$ of protein was used to measure caspase-3/9 activities using caspase-3/9 apoptosis activities (C1115/ C1158). Absorbance was then recorded using a microplate reader (Bio-Rad Laboratories) at $405 \mathrm{~nm}$.

Statistical analysis. Data are presented as mean \pm SD $(n=3)$. All date were analyzed by using ANOVA by Tukey's post test or two-tailed Student's t test. $\mathrm{P}<0.05$ was accepted as statistically significant.

\section{Results}

miR-363-3p expression in serum from patients with $R B$. To investigate the role of miRNAs in RB development and progression, the expression levels of miRNAs in RB patient serum were examined. The results of cDNA microarray analysis revealed that miR-363-3p was downregulated in the serum of patients with RB compared with the controls (Fig. 1A). RT-qPCR analysis showed that miR-363-3p serum expression was downregulated in $\mathrm{RB}$ compared with the controls (Fig. 1B). 

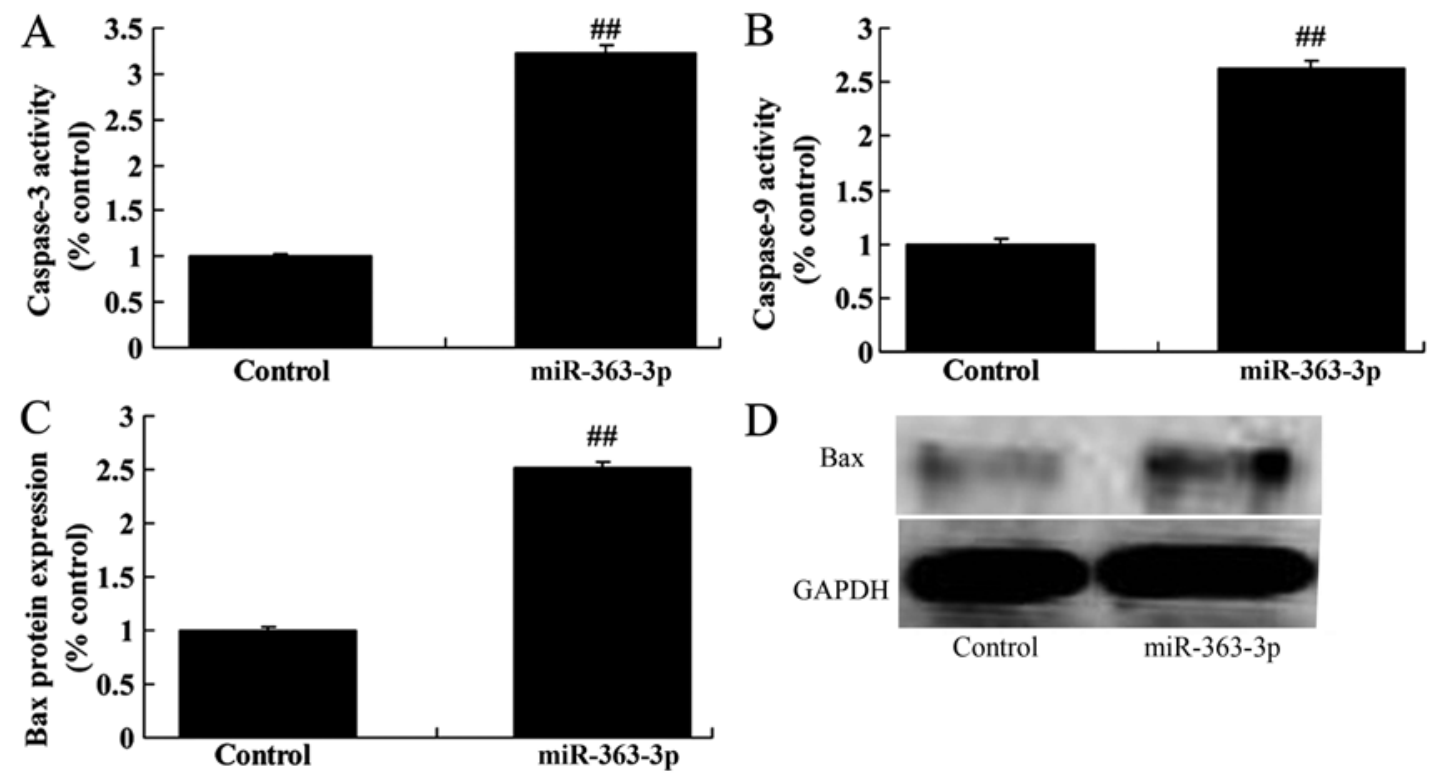

$\mathrm{D}$

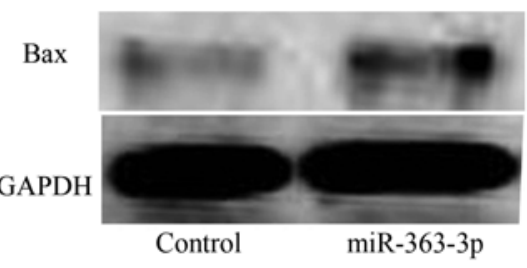

Figure 3. Overexpression of miR-363-3p in human RB WERI-Rb-1 cells induces Bax protein expression and caspase-3/9 activity. (A and B) Caspase-3/9 activity in the miR-363-3p-overexpressing RB cells. Bax protein expression (C) as determined by statistical analysis and (D) western blot analysis. Control, negative control group; miR-363-3p, miR-363-3p-overexpressing group. ${ }^{\# \#} \mathrm{P}<0.01$ compared with the negative control group. RB, retinoblastoma.

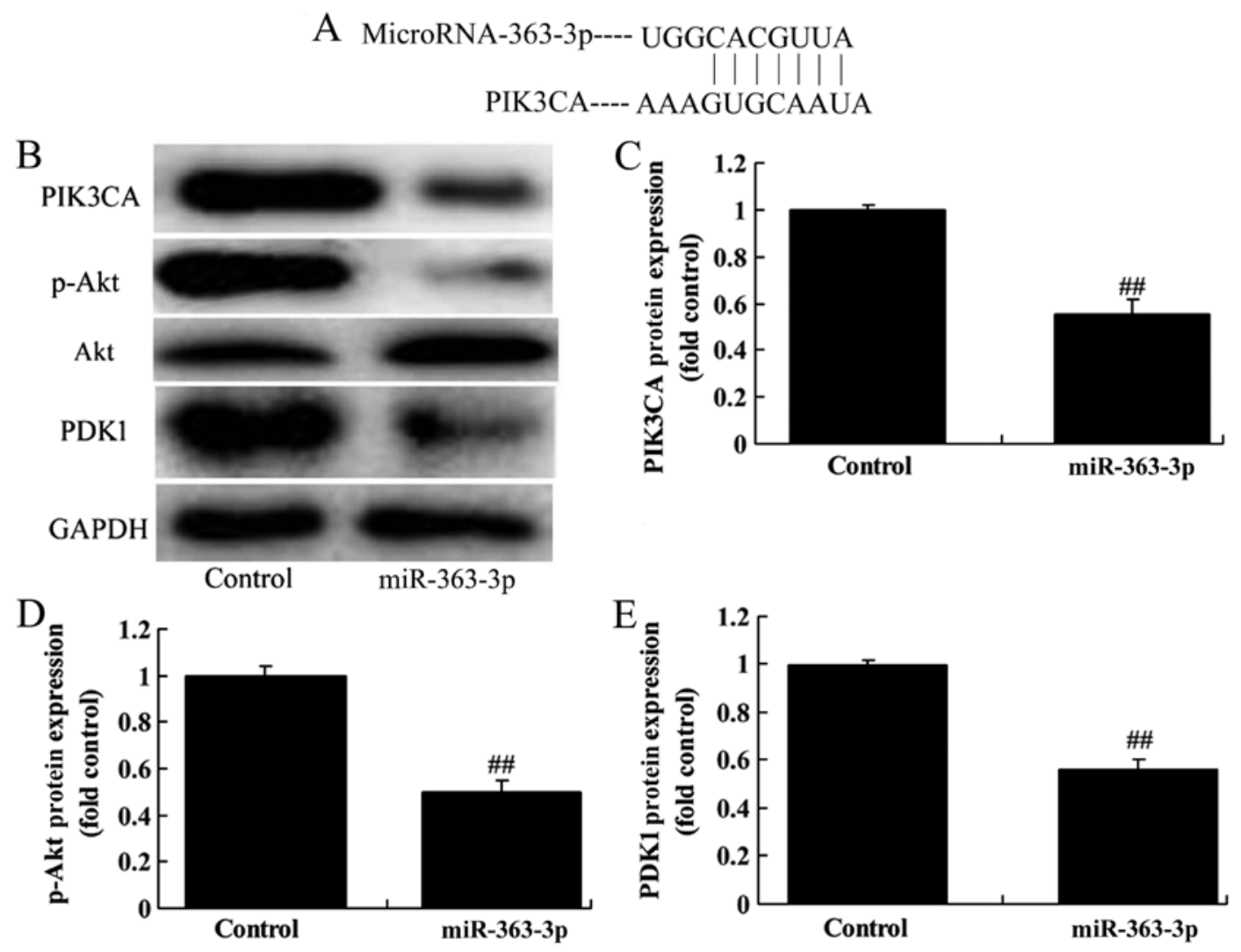

Figure 4. Overexpression of miR-363-3p suppresses PIK3CA, PDK1 and p-Akt protein expression in human RB WERI-Rb-1 cells. (A) Predicted interaction between miR-363-3p and the target site in the PIK3CA 3'-UTR. (B) PIK3CA, PDK1 and p-Akt protein expression by western blotting assay. (C-E) PIK3CA, PDK1 and p-Akt protein expression by statistical analysis. Control, negative control group; miR-363-3p, miR-363-3p-overexpressing group. ${ }^{\sharp \# P} \mathrm{P}<0.01$ compared with the negative control group. RB, retinoblastoma; PIK3CA, phosphatidylinositol-4,5-bisphosphate 3-kinase catalytic subunit $\alpha$; PDK1, pyruvate dehydrogenase kinase 1; p-AKT, phosphorylated protein kinase B.

Overexpression of miR-363-3p reduces $R B$ cell proliferation and invasion. The impact of overexpression of miR-363-3p on cell growth and invasion was investigated using RB cells. As presented in Fig. 2A, transfection with miR-363-3p mimics significantly increased miR-363-3p expression. Overexpression of miR-363-3p significantly reduced cell 

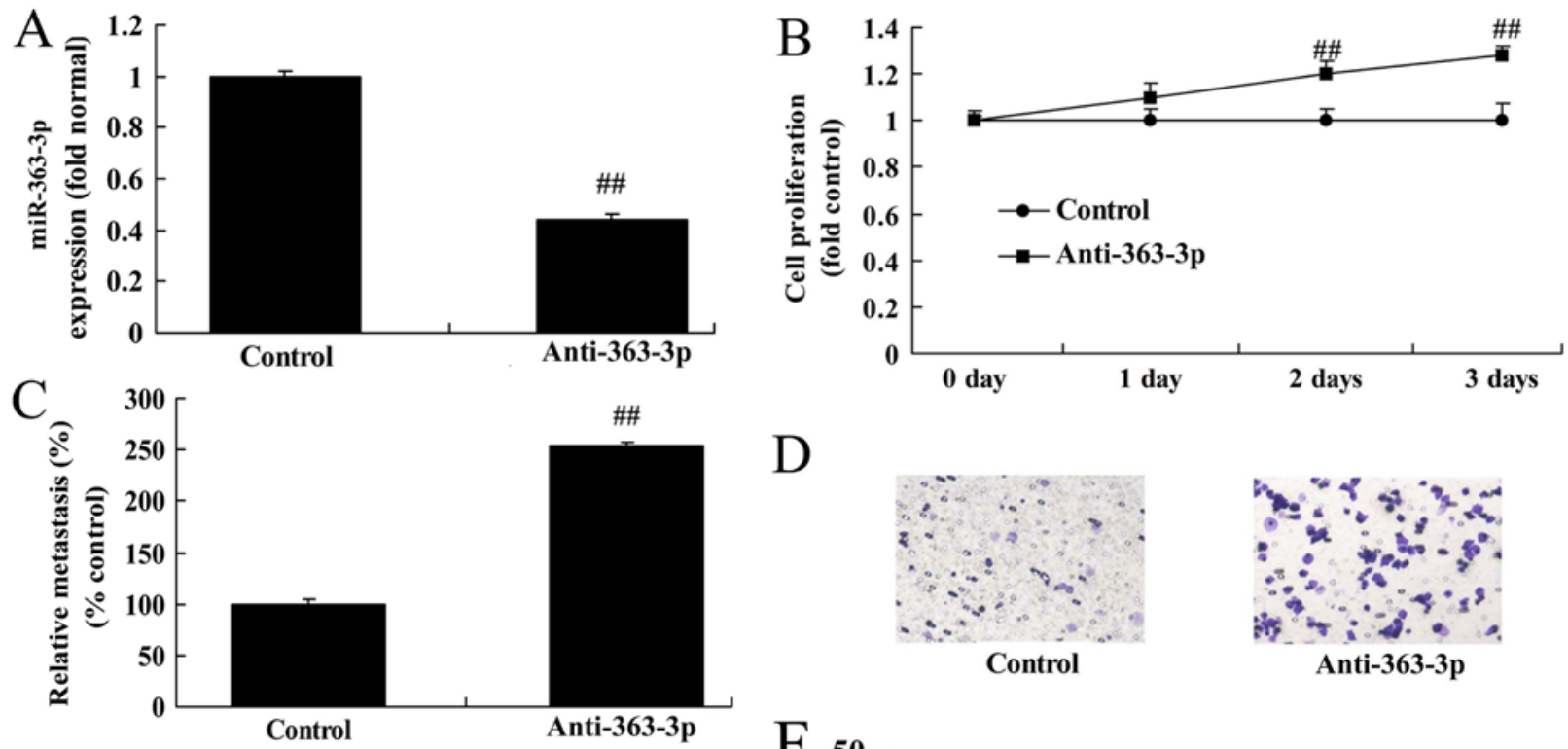

$\mathrm{D}$
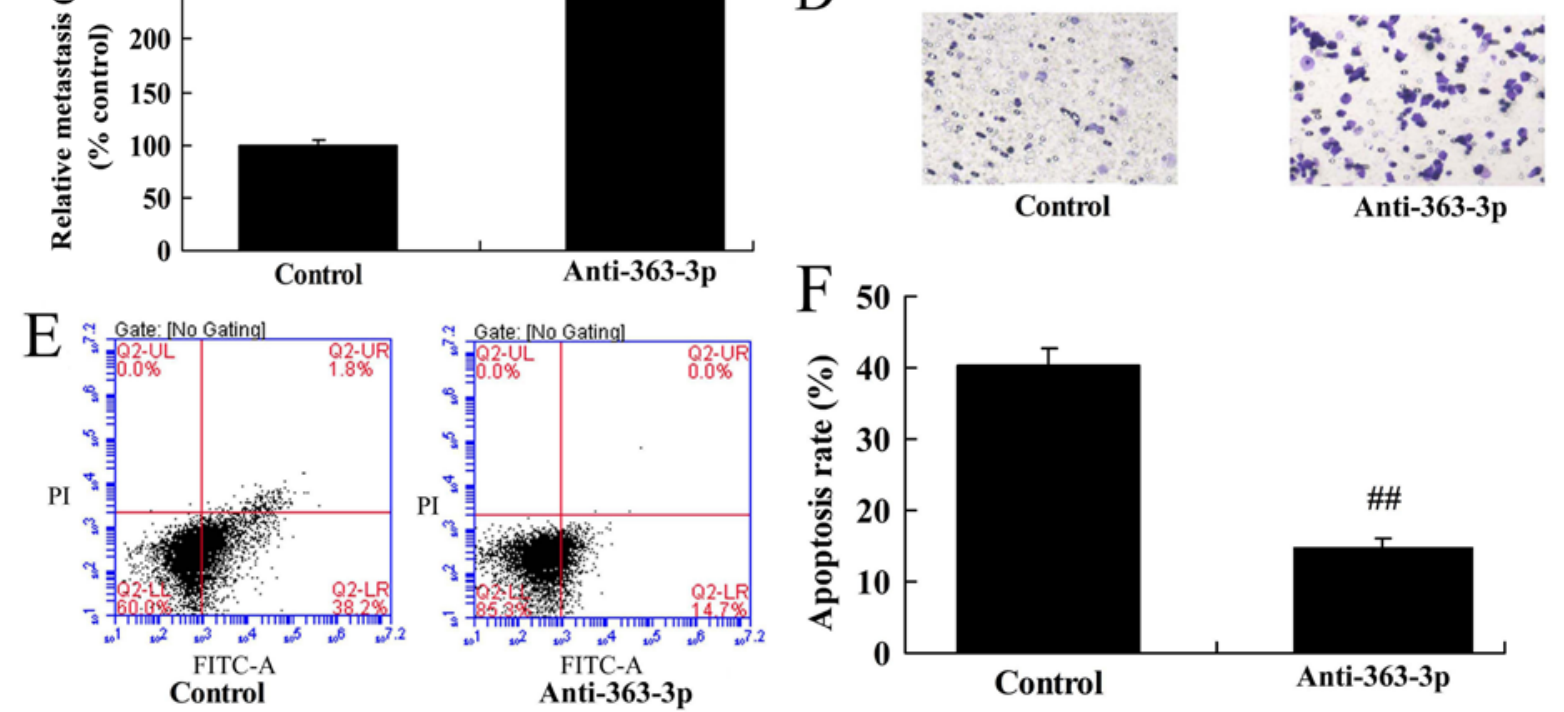

Figure 5. Downregulation of miR-363-3p promotes RB cell growth and migration in human RB WERI-Rb-1 cells. (A) miR-363-3p expression following silencing by anti-363-3p. (B) Cell proliferation and (C and D) cell invasion and (E and F) apoptosis rate in the RB cells following silencing of miR-363-3p. Control, negative control group; Anti-363-3p, miR-363-3p downregulation group. ${ }^{\# \#} \mathrm{P}<0.01$ compared with the negative control group.

growth and invasion of RB cells compared with the control group (Fig. 2B-D). In addition, overexpression of miR-363-3p significantly increased the apoptosis rate of RB cells compared with the control group (Fig. 2E and F). These findings indicate that miR-363-3p expression may influence RB development and progression, and may be involved in RB cell growth and apoptosis.

Overexpression of miR-363-3p induces BAX protein expression and caspase-3/9 activity. BAX protein expression and caspase-3/9 activity were analyzed in RB cells with miR-363-3p overexpression. Overexpression of miR-363-3p significantly induced BAX protein expression and caspase-3/9 activity compared with the control group (Fig. 3).

Overexpression of miR-363-3p suppresses PIK3CA, pyruvate dehydrogenase kinase 1 (PDK1) and phosphorylated ( $p)-A K T$ protein expression. To investigate whether miR-363-3p targets the PIK3CA signaling pathway in RB, PIK3CA, PDK1 and p-AKT protein expression levels were measured in RB cells with miR-363-3p overexpression. The predicted interaction between miR-363-3p and the target site in the $3^{\prime}$ untranslated region of PIK3CA is presented in Fig. 4A. As shown in Fig. 4B-E, overexpression of miR-363-3p significantly suppressed PIK3CA, PDK1 and p-AKT protein expression in $\mathrm{RB}$ cells compared with the control group.
Knockdown of miR-363-3p promotes $R B$ cell growth and invasion. The effects of miR-363-3p knockdown on RB cell growth and invasion were investigated. As presented in Fig. 5A, transfection with anti-miR-363-3p inhibitor (Anti-363-3p) significantly reduced the expression of miR-363-3p. Knockdown of miR-363-3p significantly promoted RB cell growth and invasion compared with the control group (Fig. 5B-D). Knockdown of miR-363-3p significantly reduced the cell apoptosis rate of the RB cells compared with the control group (Fig. 5E and F).

Knockdown of miR-363-3p suppresses BAX protein expression and caspase-3/9 activity, and induces PIK3CA, PDK1 and $p$-AKT protein expression. Knockdown of miR-363-3p significantly induced BAX protein expression and caspase-3/9 activity in RB cells, compared with the control group (Fig. 6A-D). In addition, knockdown of miR-363-3p significantly induced PIK3CA, PDK1 and p-AKT protein expression in RB cells, compared with the control group (Fig. 6E-H).

Knockdown of PIK3CA increases the anticancer effects of miR-363-3p on PIK3CA, PDK1 and p-AKT protein expression. The role of PIK3CA in the anticancer effect of miR-363-3p in regards to $\mathrm{RB}$ cell proliferation and invasion was investigated. si-PIK3CA further significantly suppressed PIK3CA, PDK1 and p-AKT protein expression in RB cells 

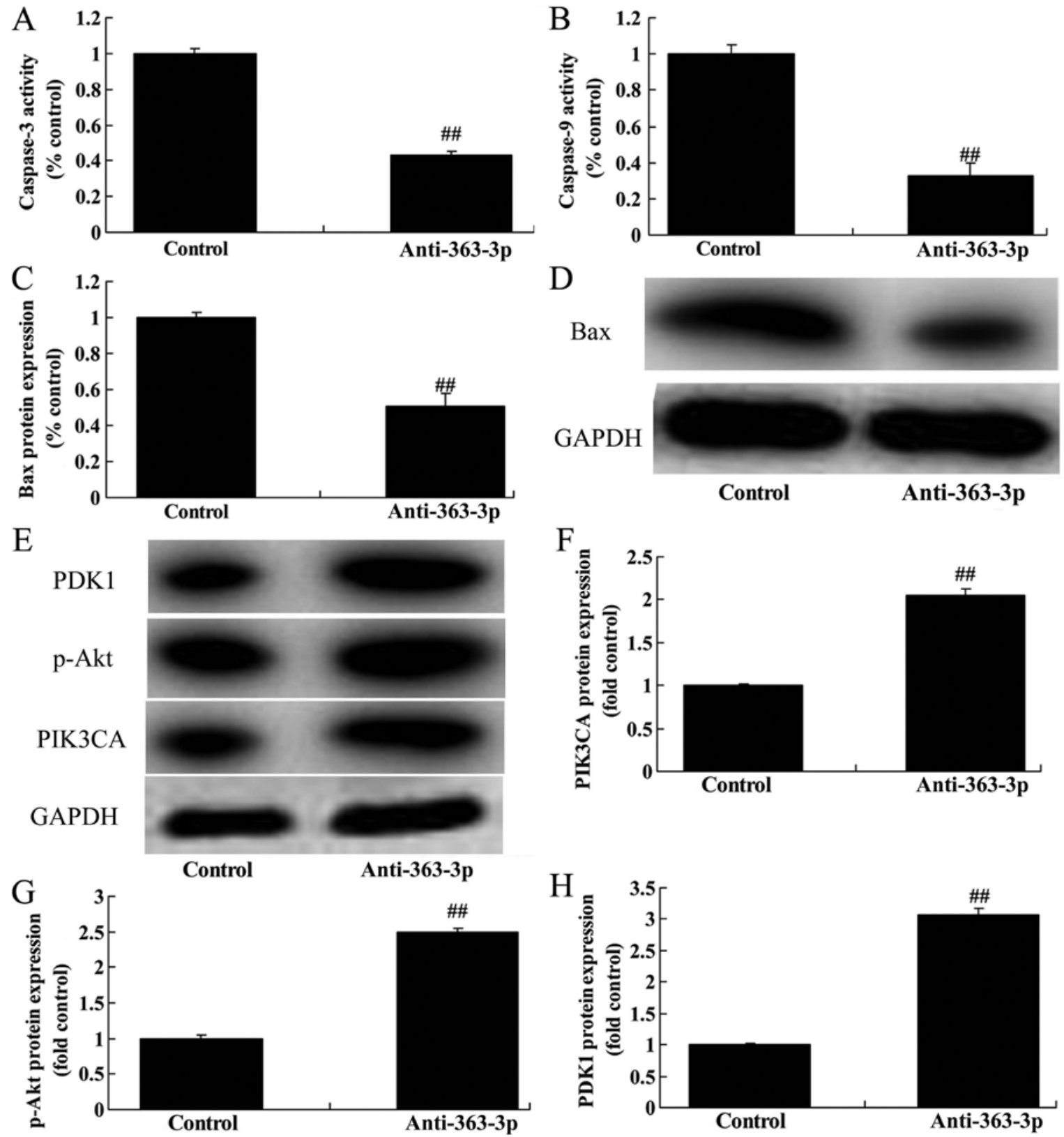

Figure 6. Downregulation of miR-363-3p suppresses Bax protein expression and caspase-3/9 activity, and induces PIK3CA, PDK1 and p-Akt protein expression in human RB WERI-Rb-1 cells. (A and B) Caspase-3/9 activity. Bax protein expression by (C) statistical analysis and (D) western blotting analysis (E) PIK3CA, PDK1 and p-Akt protein expression by western blotting assays. (F-H) PIK3CA, PDK1 and p-Akt protein expression by statistical analysis. Control, negative control group; Anti-363-3p, miR-363-3p downregulation group. ${ }^{\# \#} \mathrm{P}<0.01$ compared with the negative control group. RB, retinoblastoma; PIK3CA, phosphatidylinositol-4,5-bisphosphate 3-kinase catalytic subunit $\alpha$; PDK1, pyruvate dehydrogenase kinase 1; p-AKT, phosphorylated protein kinase B.

with miR-363-3p overexpression compared with cells with overexpression of miR-363-3p alone (Fig. 7A-D). Inhibition of PIK3CA significantly induced BAX protein expression and caspase-3/9 activity in RB cells with miR-363-3p overexpression compared with cells with overexpression of miR-363-3p alone (Fig. 7E-H).

Knockdown of PIK3CA increases the anticancer effects of miR-363-3p on RB cell proliferation and invasion. Inhibition of PIK3CA expression using si-PIK3CA significantly increased the inhibition of cell growth and invasion induced by miR-363-3p overexpression in RB cells, compared with cells with overexpression of miR-363-3p alone (Fig. 8A-C).
si-PIK3CA significantly increased the induction of apoptosis by miR-363-3p overexpression, compared with the cells with overexpression of miR-363-3p alone (Fig. 8D and E). These results suggest that PIK3CA may play a significant role in modulating the effects of miR-363-3p on RB cell growth.

Treatment with a PDK1 inhibitor accelerates the anticancer effects of miR-363-3p on $p$-AKT protein expression. To further determine whether PDK1 participates in the anticancer effects of miR-363-3p on RB cell proliferation and invasion, a PDK1 inhibitor (OSU-03012; $1 \mu \mathrm{M}$ ) was used to reduced PDK1 protein expression. As presented in Fig. 9A-C, treatment with the PDK1 inhibitor suppressed PDK1 expression and increased 

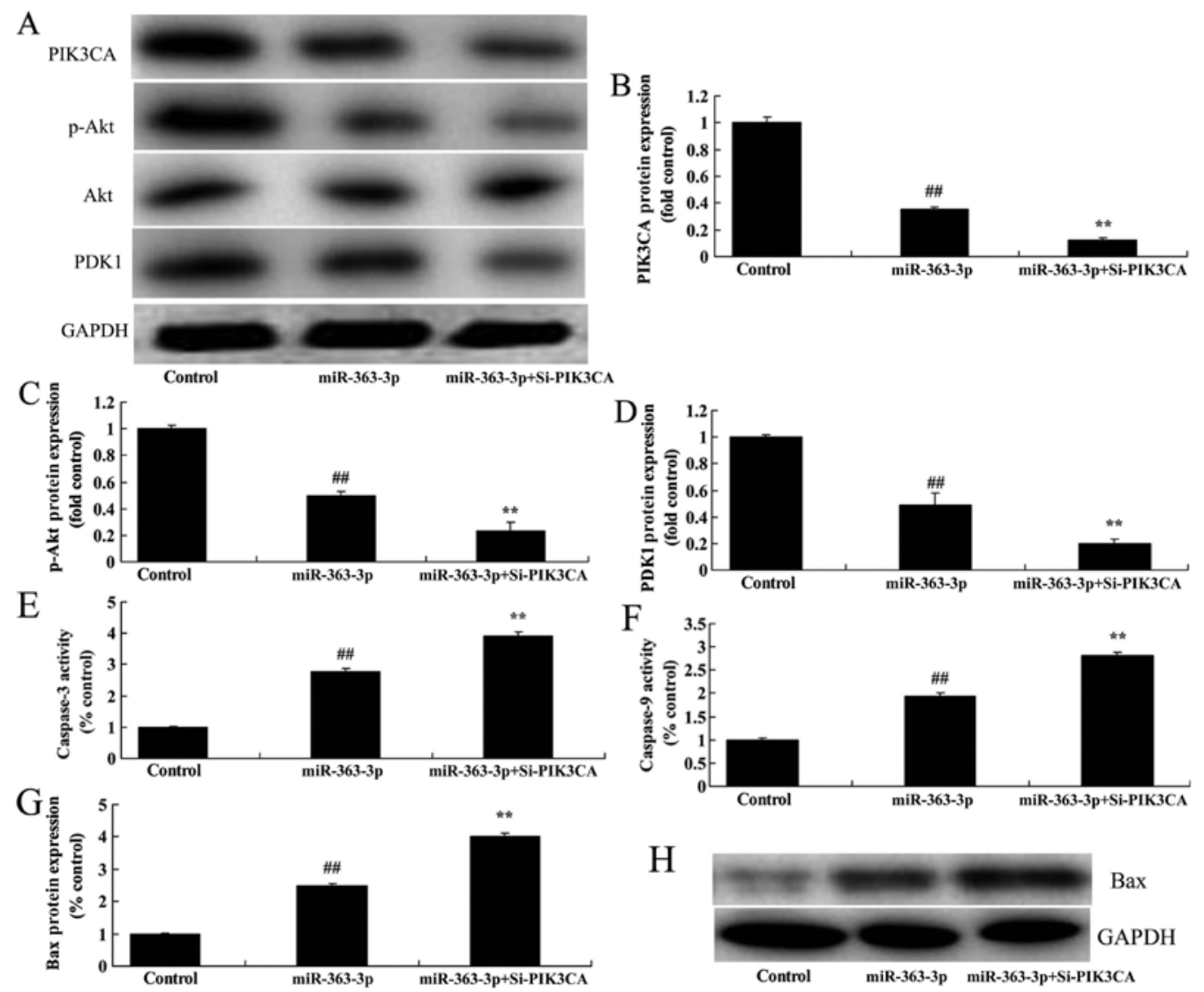

Figure 7. Silencing of PIK3CA (Si-PIK3CA) increases the anticancer effect of miR-363-3p on PIK3CA, PDK1 and p-Akt protein expression in human RB WERI-Rb-1 cells. (A) PIK3CA, PDK1 and p-Akt protein expression by western blot analysis. (B-D) PIK3CA, PDK1 and p-Akt protein expression by statistical analysis. (E and F) Caspase-3/9 activity. Bax protein expression by (G) statistical analysis and (H) western blot analysis. Control, negative control group; miR-363-3p, miR-363-3p-overexpressing group; miR-363-3p+Si-PIK3CA, miR-363-3p overexpression and Si-PIK3CA group. ${ }^{\# \#<0.01 ~ c o m p a r e d ~ w i t h ~ t h e ~}$ negative control group. ${ }^{* *} \mathrm{P}<0.01$ compared with the miR-363-3p-overexpressing group. RB, retinoblastoma; PIK3CA, phosphatidylinositol-4,5-bisphosphate 3-kinase catalytic subunit $\alpha$; PDK1, pyruvate dehydrogenase kinase 1; p-AKT, phosphorylated protein kinase B.

B
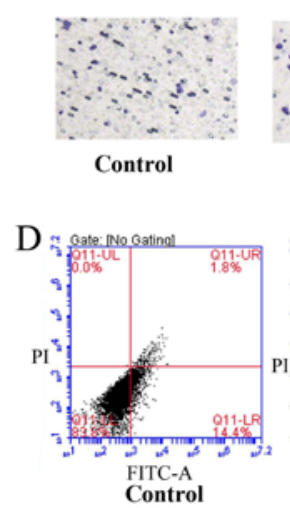

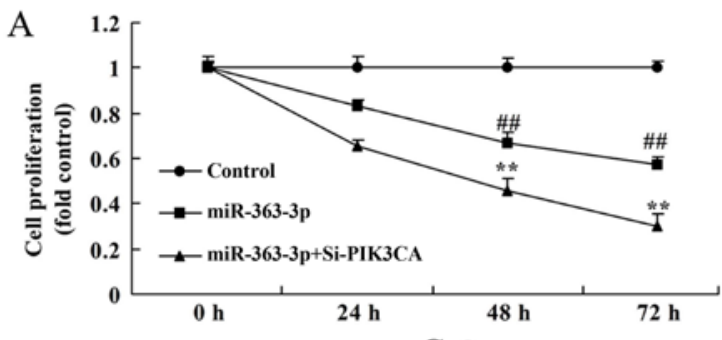

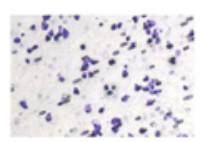

miR-363-3p

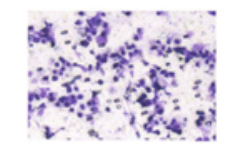
miR-363-3p+Si-PIK3CA
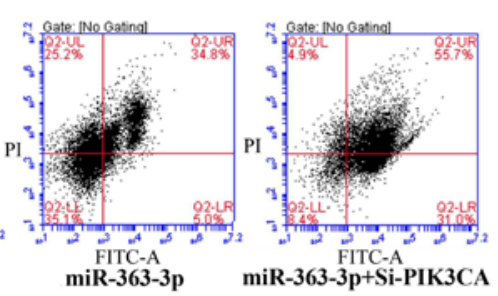
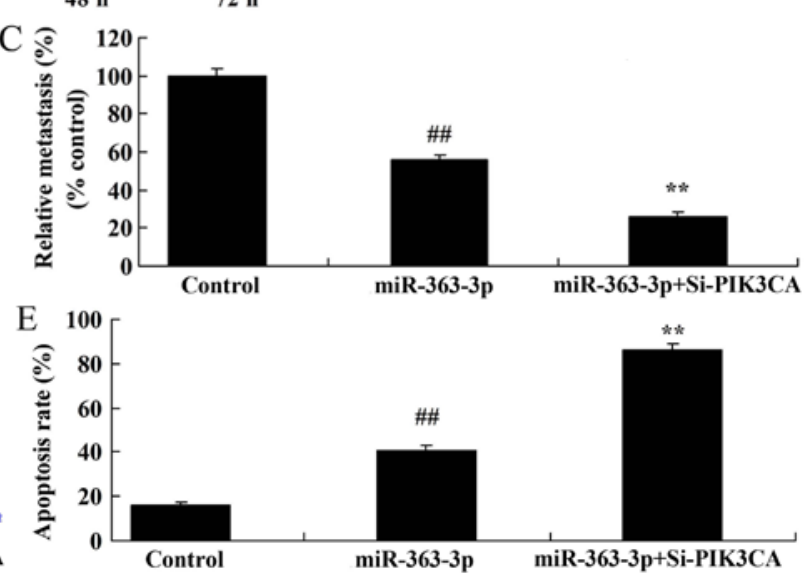

Figure 8. Silencing of PIK3CA (Si-PIK3CA) increases the anticancer effect of miR-363-3p on the proliferation and migration of human RB WERI-Rb-1 cells. (A) Cell proliferation, (B and C) cell invasion, and (D and E) apoptosis rate following silencing of PIK3CA. Control, negative control group; miR-363-3p, miR-363-3p-overexpressing group; miR-363-3p+Si-PIK3CA, miR-363-3p overexpression and Si-PIK3CA group. ${ }^{\# \#} \mathrm{P}<0.01$ compared with the negative control group, ${ }^{* *} \mathrm{P}<0.01$ compared with the miR-363-3p-overexpressing group. RB, retinoblastoma; PIK3CA, phosphatidylinositol-4,5-bisphosphate 3-kinase catalytic subunit $\alpha$. 

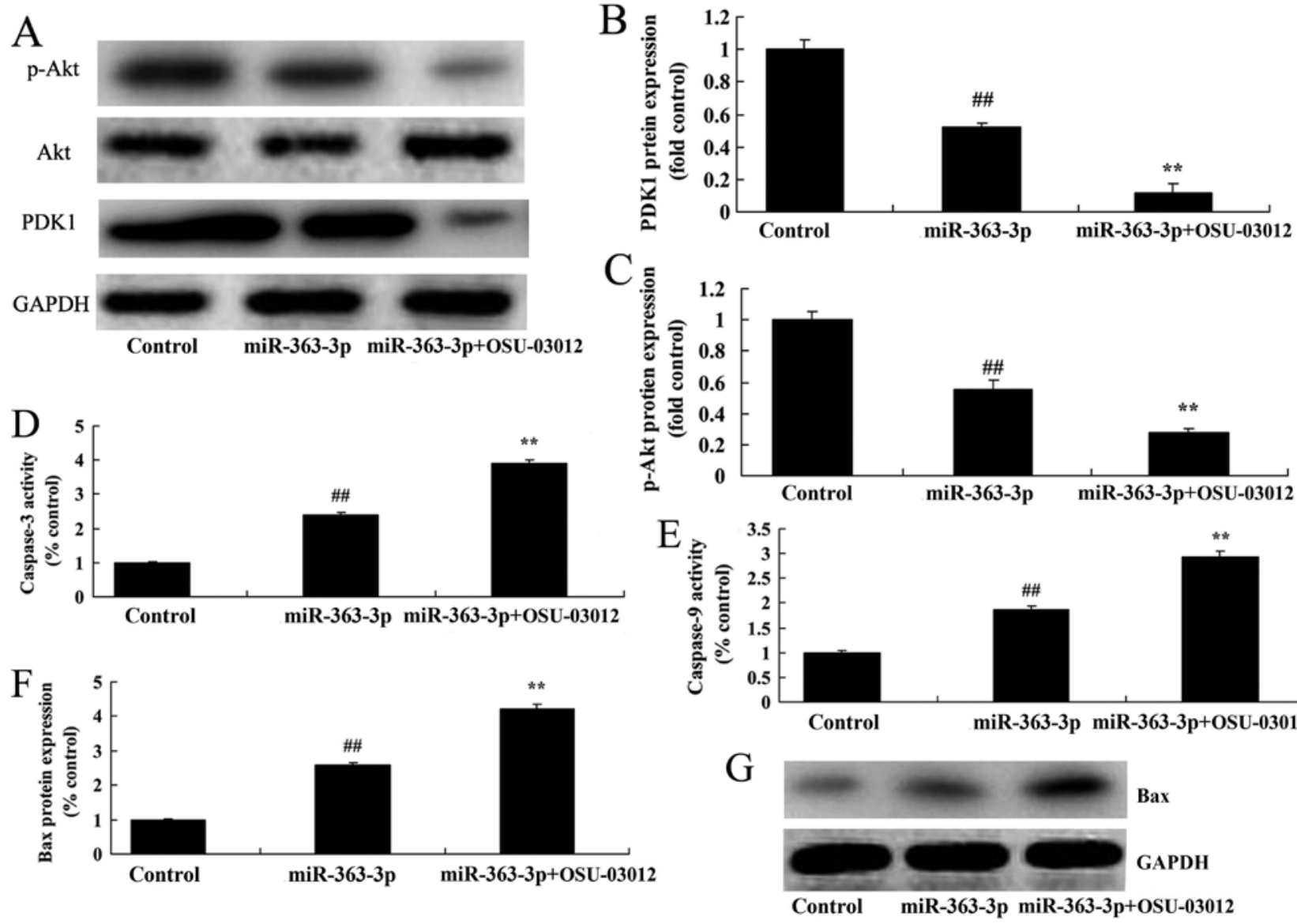

Figure 9. PDK1 inhibitor (OSU-03012) accelerates the anticancer function of miR-363-3p on PDK1 and p-Akt protein expression in human RB WERI-Rb-1 cells (A) PDK1 and p-Akt protein expression by western blot analysis. (B and C) PDK1 and p-Akt protein expression by statistical analysis. (D and E) Caspase-3/9 activity and ( $\mathrm{F}$ and $\mathrm{G}$ ) Bax protein expression. Control, negative control group; miR-363-3p, miR-363-3p-overexpressing group; miRNA-363-3p+OSU-03012, overexpression of miR-363-3p+PDK1 inhibitor group. ${ }^{\# \#} \mathrm{P}<0.01$ compared with the negative control group, ${ }^{* *} \mathrm{P}<0.01$ compared with the miR-363-3p-overexpressing group. RB, retinoblastoma; PDK1, pyruvate dehydrogenase kinase 1; p-AKT, phosphorylated protein kinase B.

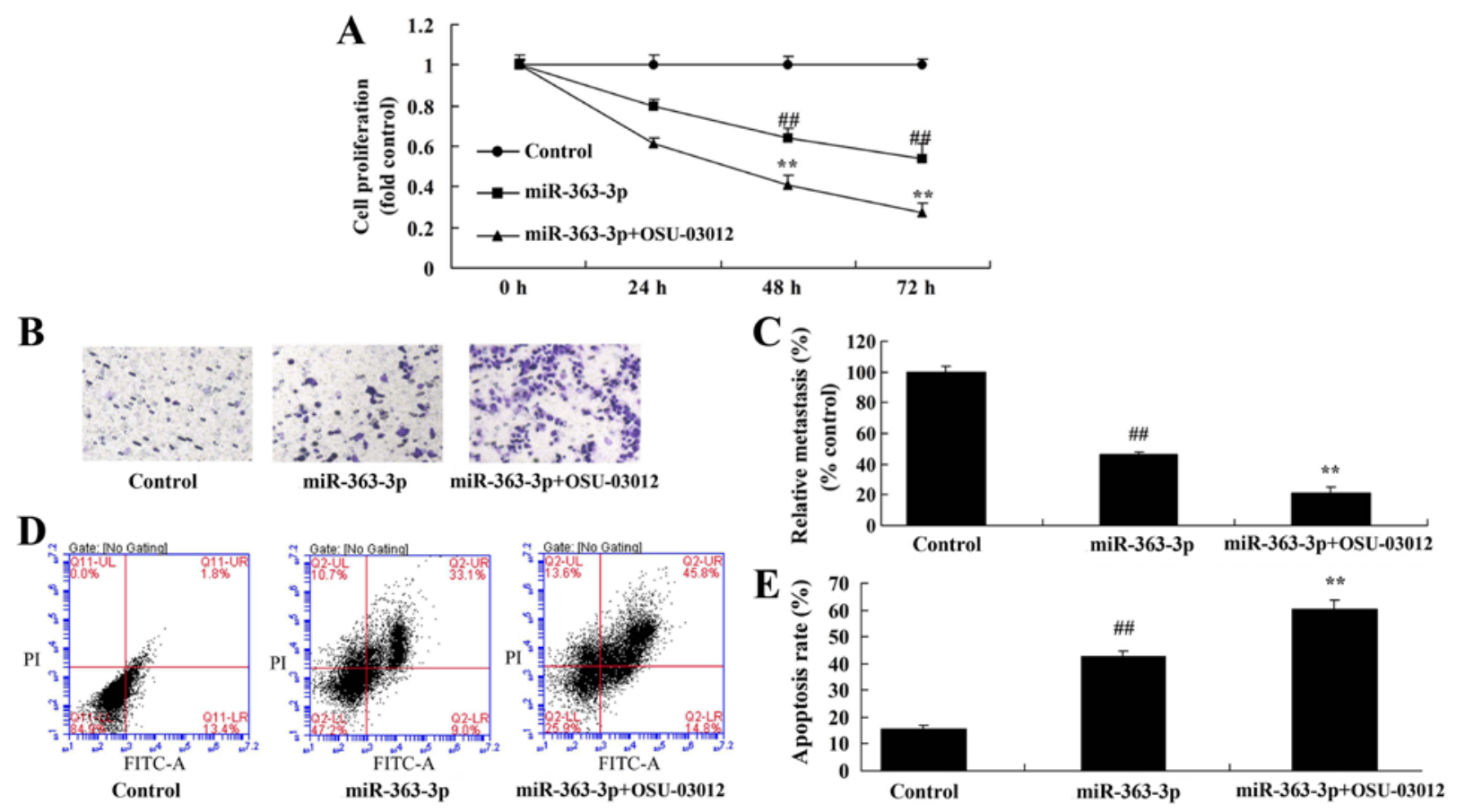

Figure 10. PDK1 inhibitor (OSU-03012) accelerates the anticancer function of miR-363-3p on RB cell proliferation and migration. (A) Cell proliferation, (B and C) invasion and (D and E) apoptosis rate. Control, negative control group; miR-363-3p, miR-363-3p-overexpressing group; miRNA-363-3p+OSU-03012, overexpression of miR-363-3p+PDK1 inhibitor group. ${ }^{\# \#} \mathrm{P}<0.01$ compared with the negative control group, ${ }^{* *} \mathrm{P}<0.01$ compared with the miR-363-3p-overexpressing group. $\mathrm{RB}$, retinoblastoma; PDK1, pyruvate dehydrogenase kinase 1. 
the suppression of p-AKT in RB cells with overexpression of miR-363-3p, compared with cells that were not treated with the inhibitor. The PDK1 inhibitor also further increased BAX protein expression and caspase-3/9 activity in RB cells with overexpression of miR-363-3p, compared with untreated cells with overexpression of miR-363-3p alone (Fig. 9D-G).

Treatment with a PDK1 inhibitor accelerates the anticancer effects of miR-363-3p on RB cell proliferation and invasion. The PDK1 inhibitor further suppressed RB cell growth and invasion in RB cells with overexpression of miR-363-3p compared with untreated cells with overexpression of miR-363-3p alone (Fig. 10A-C). Additionally, the PDK1 inhibitor increased the promotion of apoptosis by miR-363-3p compared with untreated cells with overexpression of miR-363-3p alone (Fig. 10D and E).

\section{Discussion}

$\mathrm{RB}$ is the most common type of intraocular malignancy among children, with poor prognosis, seriously affecting patient vision and even threatening their lives. The pathogenesis is generally considered to be the second mutation of the $R B$ gene (4). With the progress of research, through a deeper exploration of the pathogenic molecular biology of RB and other tumors, it has been suggested that RB is associated with changes in multiple signaling pathways, but the specific pathogenesis of this disease remains uncertain (12). The findings of the present study revealed that miR-363-3p expression was upregulated in serum from patients with RB. A study by Liu et al (11) showed that miR-363-3p inhibits cell growth of papillary thyroid carcinoma. The findings of the current study are limited by the small sample size of patients and normal samples, which was 6. More clinical cases will be investigated in future studies.

Bcl-2 is an inhibitor of apoptosis. It is an endogenous inhibitor of mitochondrial membrane permeability (13). Expressed in proliferating cells, Bcl-2 plays an important role in the maintenance of cell metabolism (14). Chromosome translocation can lead to upregulation of Bcl-2, blocking the activation of the protease chain reaction and prolonging cell survival through stopping the release of cytochrome $c$ from the mitochondria, so that the balance of cell proliferation and apoptosis is disturbed, leading to the development of tumors (15). Studies have shown that activation of pyruvate dehydrogenase kinase 1 (PDK1) by phosphorylation induces the apoptosis of cells by affecting mitochondrial damage and regulating $\mathrm{Bcl}-2, \mathrm{Bcl}-\mathrm{xL}$ and survivin $(15,16)$. In the present study, overexpression of miR-363-3p reduced RB cell proliferation and invasion.

The P110a-PI3K catalytic subunit of the phosphatidylinositol-4,5-bisphosphate 3-kinase catalytic subunit $\alpha$ (PIK3CA) gene has been studied in human cancer for more than 15 years (17). Several studies have shown that PI3K kinase activity is closely related to the key oncogenic protein P110a, which plays an important role in tumor formation $(8,17,18)$. The phosphoinositide 3-kinase (PI3K) pathway is activated by PIK3CA mutation or amplification $(8,17)$. Activated PI3K generates a second messenger to activate a series of downstream protein kinases, including AKT, leading to further signal transmission, and therefore, the PDK signaling pathway has a significant effects on cell proliferation, apoptosis, migration, vesicular transport and malignant transformation of cells and many other pathophysiological processes (18). The $\mathrm{PI} 3 \mathrm{~K} / \mathrm{AKT} / \mathrm{PKB}$ signal transduction pathway is particularly important for the modulation of apoptosis (19). In the present study, overexpression of miR-363-3p suppressed PIK3CA, PDK1 and p-AKT protein expression. Liu et al (11) showed that miR-363-3p inhibits cell growth of papillary thyroid carcinoma through the PIK3CA/AKT signaling pathway.

PDK1 is a $63-\mathrm{kDa}$ serine/threonine protein kinase that includes a C-terminal platelet-leukocyte C-kinase substrate homology domain and an N-terminal kinase domain (20). The $\mathrm{PH}$ domain combines with the PI3K product inositol triphosphate, targeting PDK1 to the membrane and activating AKT, thereby acting on a variety of downstream substrates such as NF-KB, caspase-9 and endothelial nitric oxide synthase, and subsequently affecting cell growth, migration, apoptosis and angiogenesis, as well as other biological effects (21). PDK1-mediated PI3K/AKT signaling pathways have been associated with multiple types of malignant tumor (18). In the present study, inhibition of PIK3CA or PDK1 was found to accelerate the anticancer effects of miR-363-3p on RB through PI3K/AKT signaling. Based on the results of the present study, the mechanism of miR-363-3p/PI3K/AKT signaling in RB is unclear. Therefore, more signaling pathways, including GSK-3, FOXO1 and mTORC1, will be investigated in further studies.

In summary, the results of this study revealed that overexpression of miR-363-3p reduced the proliferation and invasion of RB cells through suppression of the PIK3CA/PI3K/AKT pathway. These findings suggest that enhancing the expression of a single miRNA, miR-363-3p may significantly improve the efficacy of treatment for RB and possibly other solid tumors.

\section{Acknowledgements}

Not applicable.

\section{Funding}

No funding was received.

\section{Availability of data and materials}

The datasets used during the present study are available from the corresponding author upon reasonable request.

\section{Authors' contributions}

LJ designed the experiments; XM, XL, JT and RW performed the experiment; XM and LJ analyzed the data; XM wrote the manuscript. All authors read, reviewed and approved the manuscript and agree to be accountable for all aspects of the research in ensuring that the accuracy or integrity of any part of the work are appropriately investigated and resolved.

\section{Ethics approval and consent to participate}

The study protocol was approved by the Medical Ethics Committee of Xi'an Traditional Chinese Medicine Hospital (Xi'an, Shaanxi, China). 


\section{Patient consent for publication}

Not applicable.

\section{Competing interests}

The authors state that they have no competing interests.

\section{References}

1. Kommoss S, du Bois A, Ridder R, Trunk MJ, Schmidt D, Pfisterer J and Kommoss F; AGO-OVAR: Independent prognostic significance of cell cycle regulator proteins p16(INK4a) and $\mathrm{pRb}$ in advanced-stage ovarian carcinoma including optimally debulked patients: A translational research subprotocol of a randomised study of the arbeitsgemeinschaft gynaekologische onkologie ovarian cancer study group. Br J Cancer 96: 306-313, 2007.

2. Lumbroso-Le Rouic L, Aerts I, Hajage D, Lévy-Gabriel C, Savignoni A, Algret N, Cassoux N, Bertozzi AI, Esteve M, Doz F and Desjardins L: Conservative treatment of retinoblastoma: A prospective phase II randomized trial of neoadjuvant chemotherapy followed by local treatments and chemothermotherapy. Eye (Lond) 30: 46-52, 2016.

3. DeMichele A, Clark AS, Tan KS, Heitjan DF, Gramlich K, Gallagher M, Lal P, Feldman M, Zhang P, Colameco C, et al: CDK 4/6 inhibitor palbociclib (PD0332991) in Rb+ advanced breast cancer: Phase II activity, safety, and predictive biomarker assessment. Clin Cancer Res 21: 995-1001, 2015.

4. Martin J, Bryar P, Mets M, Weinstein J, Jones A, Martin A, Vanin EF, Scholtens D, Costa FF, Soares MB and Laurie NA: Differentially expressed miRNAs in retinoblastoma. Gene 512: 294-299, 2013.

5. Wei Y, Sun J and Li X: MicroRNA-215 enhances invasion and migration by targeting retinoblastoma tumor suppressor gene 1 in high-grade glioma. Biotechnol Lett 39: 197-205, 2017.

6. Liu SS, Wang YS, Sun YF, Miao LX, Wang J, Li YS, Liu HY and Liu QL: Plasma microRNA-320, microRNA-let-7e and microRNA-21 as novel potential biomarkers for the detection of retinoblastoma. Biomed Rep 2: 424-428, 2014.

7. Qi L, Zhu F, Li SH, Si LB, Hu LK and Tian H: Retinoblastoma binding protein 2 (RBP2) promotes HIF- $1 \alpha$-VEGF-induced angiogenesis of non-small cell lung cancer via the Akt pathway. PLoS One 9: e106032, 2014

8. Xiao W, Chen X and He M: Inhibition of the Jagged/Notch pathway inhibits retinoblastoma cell proliferation via suppressing the PI3K/Akt, Src, p38MAPK and Wnt/ $\beta$-catenin signaling pathways. Mol Med Rep 10: 453-458, 2014.

9. Eo SH, Kim JH and Kim SJ: Induction of $\mathrm{G}_{2} / \mathrm{M}$ arrest by berberine via activation of PI3K/Akt and p38 in human chondrosarcoma cell line. Oncol Res 22: 147-157, 2014.
10. Gui F, Hong Z, You Z, Wu H and Zhang Y: MiR-21 inhibitor suppressed the progression of retinoblastoma via the modulation of PTEN/PI3K/AKT pathway. Cell Biol Int 40: 1294-1302, 2016.

11. Liu J, Li Q, Li R, Ren P and Dong S: MicroRNA-363-3p inhibits papillary thyroid carcinoma progression by targeting PIK3CA. Am J Cancer Res 7: 148-158, 2017.

12. Friedman DN, Lis E, Sklar CA, Oeffinger KC, Reppucci M, Fleischut MH, Francis JH, Marr B, Abramson DH and Dunkel IJ: Whole-body magnetic resonance imaging (WB-MRI) as surveillance for subsequent malignancies in survivors of hereditary retinoblastoma: A pilot study. Pediatr Blood Cancer 61: 1440-1444, 2014.

13. Song W, Liu MG, Zhang JB, Zhang JJ, Sun MM and Yu QK: Mechanism of action of EBV, Bcl-2, p53, c-Myc and Rb in non-Hodgkin's lymphoma. Eur Rev Med Pharmacol Sci 20: 1093-1097, 2016.

14. Singh L, Pushker N, Saini N, Sen S, Sharma A, Bakhshi S, Chawla B and Kashyap S: Expression of pro-apoptotic Bax and anti-apoptotic Bcl-2 proteins in human retinoblastoma. Clin Exp Ophthalmol 43: 259-267, 2015.

15. La Thangue NB: A mismatched role for Bcl-2. Nat Cell Biol 7: 101-102, 2005.

16. Lai JH, Fleming KE, Ly TY, Pasternak S, Godlewski M, Doucette S and Walsh NM: Pure versus combined Merkel cell carcinomas: Immunohistochemical evaluation of cellular proteins (p53, Bcl-2, and c-kit) reveals significant overexpression of p53 in combined tumors. Hum Pathol 46: 1290-1296, 2015.

17. Wang G, Cao X, Lai S, Luo X, Feng Y, Xia X, Yen PM, Gong J and Hu J: PI3K stimulates DNA synthesis and cell-cycle progression via its p55PIK regulatory subunit interaction with PCNA. Mol Cancer Ther 12: 2100-2109, 2013.

18. Tomosugi M, Sowa Y, Yasuda S, Tanaka R, te Riele H, Ikawa H, Koyama M and Sakai T: Retinoblastoma gene-independent G1 phase arrest by flavone, phosphatidylinositol 3-kinase inhibitor, and histone deacetylase inhibitor. Cancer Sci 103: 2139-2143, 2012.

19. Wei TY, Juan CC, Hisa JY, Su LJ, Lee YC, Chou HY, Chen JM, Wu YC,Chiu SC,Hsu CP, et al: Protein arginine methyltransferase 5 is a potential oncoprotein that upregulates G1 cyclins/cyclin-dependent kinases and the phosphoinositide 3-kinase/AKT signaling cascade. Cancer Sci 103: 1640-1650, 2012.

20. Vora SR, Juric D, Kim N, Mino-Kenudson M, Huynh T, Costa C, Lockerman EL, Pollack SF, Liu M, Li X, et al: CDK 4/6 inhibitors sensitize PIK3CA mutant breast cancer to PI3K inhibitors. Cancer Cell 26: 136-149, 2014.

21. Choy E,HornicekF, MacConaillL,Harmon D, TariqZ, Garraway L and Duan Z: High-throughput genotyping in osteosarcoma identifies multiple mutations in phosphoinositide-3-kinase and other oncogenes. Cancer 118: 2905-2914, 2012.

(i) $(-)$ This work is licensed under a Creative Commons Attribution-NonCommercial-NoDerivatives 4.0 International (CC BY-NC-ND 4.0) License. 